\begin{tabular}{|c|l|}
\hline Title & Establishment of cell lines that exhibit pluripotency from miniature swine periodontal ligaments. \\
\hline Author(s) & $\begin{array}{l}\text { Ibi, Miho; Ishisaki, A kira; Y amamoto, Matsuo; Wada, Satoshi; Kozakai, Takaharu; Nakashima, A iko; lida, Jynichiro; } \\
\text { Takao, Sonshin; Izumi, Y uichi; Y okoyama, A tsuro; Tamura, Masato }\end{array}$ \\
\hline Citation & $\begin{array}{l}\text { Archives of Oral Biology, 52(10), 1002-1008 } \\
\text { https://doi.org/10.1016/.archoralbio.2007.04.009 }\end{array}$ \\
\hline Issue Date & 2007-10 \\
\hline Doc URL & http://hdl.handle.net/2115/28279 \\
\hline Type & article (author version) \\
\hline File Information & A OB52-10.pdf \\
\hline
\end{tabular}

Instructions for use 


\section{Establishment of cell lines that exhibit pluripotency from miniature swine periodontal ligaments}

Miho Ibi ${ }^{\text {a, b }}$, Akira Ishisaki ${ }^{\text {a }}$, Matsuo Yamamoto ${ }^{c}$, Satoshi Wada ${ }^{\mathrm{d}}$, Takaharu Kozakai ${ }^{\mathrm{e}}$, Aiko Nakashima ${ }^{\mathrm{a}}$, Jynichiro Iida ${ }^{\mathrm{d}}$, Sonshin Takao ${ }^{\mathrm{f}}$, Yuichi Izumi ${ }^{\mathrm{g}}$, Atsuro Yokoyama ${ }^{\mathrm{b}}$ and Masato Tamura ${ }^{\mathrm{a}^{*}}$

${ }^{a}$ Department of Oral Biochemistry and Molecular Biology, Graduate School of Dental Medicine, Hokkaido University, Sapporo, Japan

${ }^{b}$ Department of Oral Functional Science, Graduate School of Dental Medicine, Hokkaido University, Sapporo, Japan

${ }^{c}$ Department of Periodontology, Showa University School of Dentistry, Tokyo, Japan

${ }^{\mathrm{d}}$ Department of Orthodontics, Graduate School of Dental Medicine, Hokkaido University, Sapporo, Japan

${ }^{\mathrm{e}}$ National Aguriculture and Food Research Organization, National Aguricultural Research Center for Hokkaido Region, Sapporo, Japan

${ }^{\mathrm{f}}$ Frontier Science Research Center, Kagoshima University, Kagoshima, Japan

${ }^{g}$ Division of Periodontology, Kagoshima University Graduate School of Medical and Dental Sciences, kagoshima, Japan

Running title: Cell lines from miniature swine periodontal ligaments

*To whom correspondence:

Masato Tamura, DDS, Ph.D.

Department of Oral Biochemistry and Molecular Biology

Graduate School of Dental Medicine

Hokkaido University

North 13, West 7, Sapporo 060-8586, Japan

Phone: +81-11-706-4231

Fax: +81-11-706-4877

E-mail: mtamura@den.hokudai.ac.jp 


\section{ABSTRACT}

\section{Objective}

The periodontal ligament (PDL) is a fibrous connective tissue composed of heterogeneous cell types, including PDL fibroblasts. It is not clear whether cells within the PDL fibroblast population retain the potency to differentiate into other cell types.

\section{Design}

In the present study, clonal cell lines, derived from Clawn miniature swine PDLs, were established by gene transfection for a human telomerase reverse transcriptase, and characterized.

\section{Results}

These cell lines, denoted TesPDL1-4, had PDL fibroblasts that showed fibroblastic morphology and expressed procollagen $\alpha 1(\mathrm{I})$, osteopontin, periostin and alkaline phosphatase mRNA. Under the specific culture conditions, TesPDL3 cells also have the ability to express CD31, vascular endothelial cadherin, von Willebrand factor, osteocalcin, and to form extracellular mineralized nodules.

\section{Conclusions}

Our data indicate that TesPDL3 cells have unique properties of expressing several phenotype of fibroblasts, vascular endothelial cells and osteoblasts in cultures. 
Key Words: periodontal ligaments; endothelial cells; osteoblasts; miniature swine; von Willebrand factor; CD31

Abbreviations: PDL, periodontal ligament; VE-cadherin, vascular endothelial-cadherin; vWF, von Willebrand factor; hTERT, human telomerase reverse transcriptase; MEM, minimum essential medium; FBS, fetal bovine serum; FGF, fibroblast growth factor; RT-PCR, reverse transcription polymerase chain reaction; Runx, Runt-related transcription factor; ALP, alkaline phosphatase. 


\section{INTRODUCTION}

The periodontal ligament (PDL) is a fibrous connective tissue between tooth cementum and surrounding alveolar bone and functions to support the teeth. The PDL tissue also contains microvessels and may have a role in tissue homeostasis and repair. To accomplish these functions, the PDL contains a range of heterogeneous cell types including PDL fibroblasts, osteoblasts, cementoblasts, epithelial cells (rests of Malassez), vascular endothelial cells $[1,2]$. The PDL has the capacity to reconstruct periodontal structure in response to pathological or physiological changes in the oral environment, such as, wound healing and regeneration due to periodontitis. Given this role in tissue reconstruction, it may be certain that the PDL contain pluripotent progenitor cells or putative stem cells. Mouse molar PDL has a slowly dividing population of progenitor cells in paravascular sites [3]. The paravascular zones in the adult PDL comprise the progenitors for the fibroblastic lineage and the osteoblastic and cementoblastic lineages that are responsible for formation of mineralized tissue [3]. Recently, several studies have indicated that PDL fibroblastic cells and bone marrow mesenchymal cells share common biological characteristics suggesting that the fibroblastic lineages and mineralized tissue-forming cells may originate from the same early progenitor cells $[4,5,6]$. Seo et al. (2004) also demonstrated that PDL cells show cementoblastic/osteoblastic and 
adipogenic differentiation in vitro, and have the potential to generate cementum/PDL-like tissue in vivo [7]. Although this suggests that mesenchymal stem cells are present in the PDL tissue, these have yet to be fully characterized.

Ligaments are a short bandle of tough fibrous connective tissue composed mainly of long, stringy collagen fibres. In a joint structure, bones were connected by ligaments. The specific character to PDL is highly vascularized compared to other ligaments, such as the cruciate and collateral ligaments of the knee. Vascular endothelial cells form the inner lining of blood vessels and provide an anticoagulant barrier between blood vessel walls and the blood, and play an important role in angiogenesis and vasculogenesis. Endothelial cells are thought to arise from the splanchnopleuric mesoderm and are characterized by expression of CD31 (termed platelet endothelial cell adhesion molecule-1), vascular endothelial-cadherin (VE-cadherin) and von Willebrand factor (vWF) [8]. vWF is synthesized through a multistep process in endothelial cells and is stored in organelles called Weibel-Palade bodies [9]. vWF has two main functions in hemostasis: it mediates platelet adhesion to the injured vessel wall, and it carries and protects coagulation factor VIII [9].

Recent studies on the reconstruction/regeneration of the PDL have suggested that endothelial cells have a role in this process. Angiogenesis in the PDL appears to be 
crucial for tissue reconstruction [10]. However, it is not shown that expression of phenotype of endothelial cells and such regulation of differentiation in PDL cells. To elucidate whether progenitor cells in the PDL tissue could differentiate into these endothelial cells, we isolated cell lines that were cultured from miniature swine PDL and were immortalized by overexpression of human telomerase reverse transcriptase (hTERT) and investigated expression of CD31, VE-cadherin and vWF in these cells. This is the first report of inducible expression of the endothelial cell and osteoblast phenotype by PDL fibroblasts in culture. 


\section{MATERIALS AND METHODS}

Isolation of primary PDL cells and cell culture procedures

A premolar was extracted from the mandible of a Clawn miniature swine and PDL cells were obtained using the method of Somerman et al. (1988) [11]. The donor swine, a 28-month-old male, was provided by the Japan Farm Co. (Kagoshima, Japan). Tissue from the central position of the resected root surface was immediately rinsed several times in minimum essential medium (MEM; Sigma) containing 1,000 units/ml penicillin G (Banyu Pharmaceutical Co., Tokyo, Japan), 1,000 $\mu \mathrm{g} / \mathrm{ml}$ streptomycin (Meiji Seika, Tokyo, Japan) and $5 \mu \mathrm{g} / \mathrm{ml}$ amphotericin B (Banyu), and then transferred onto culture dishes coated with type I collagen (Sumilon Celltight multi-well plate; Sumitomo Bakelite Co., Tokyo, Japan). The tissue was cultured in MEM supplemented with 10\% fetal bovine serum (FBS; Moregate Biotech, Bulimba, Australia), 100 units/ml penicillin $\mathrm{G}, 100 \mu \mathrm{g} / \mathrm{ml}$ streptomycin, and $1 \mathrm{ng} / \mathrm{ml}$ human recombinant fibroblast growth factor (FGF) 2 (Toyobo, Osaka, Japan). Outgrowth cells were cultured in a humidified atmosphere of $5 \% \mathrm{CO}_{2}$ and $95 \%$ air at $37^{\circ} \mathrm{C}$ for 5 weeks. The cells were treated with $0.05 \%$ trypsin and $0.53 \mathrm{mM}$ EDTA (Invitrogen) and sub-cultured into dishes coated with type I collagen in F-12 HAM (Sigma) supplemented with 10\% FBS, 100 units/ml penicillin G, $100 \mu \mathrm{g} / \mathrm{ml}$ streptomycin and anti-mycoplasmic antibiotic MC-210 
(Dainihon-Sumitomo Pharmaceutical Co., Osaka, Japan), and 1ng/ml of FGF2 in a humidified atmosphere of $5 \% \mathrm{CO}_{2}$ and $95 \%$ air at $37^{\circ} \mathrm{C}$.

Transfection of primary cell cultures and isolation of single clones

After three passages, cells were seeded on a type I collagen coated dish at a density of $1 \times 10^{5}$ cells $/ \mathrm{ml}$ and cultured until they were sub-confluent. The cells were transfected by the calcium phosphate procedure with pCI-Neo-hTERT plasmid (kind gift of Dr. Weinberg, Whitehead Institute for Biomedical Research, Massachusetts Institute of Technology, MA) [12]. The pCI-Neo-hTERT plasmid carries a strong constitutive cytomegalovirus promoter and a neomycin gene to confer resistance to G418 sulfate to enable selection of stable transfectants. Seven days after transfection, the cells were replated at a low density and $1 \mathrm{mg} / \mathrm{ml}$ of geneticin (G418, Promega, Madison, WI) was added to the culture medium. Resistant clones were recovered after an additional 10 days of selection. Limiting dilution clones were obtained by plating the parental cells into 96-well tissue culture plates at one cell per well. In total, 27 clonal cell lines were obtained and designated TesPDL cells.

Culture of TesPDL cells 
TesPDL3 cells were plated in type I collagen coated plastic culture dishes at $37^{\circ} \mathrm{C}$ and $5 \% \mathrm{CO}_{2}$ in humidified air and maintained in F-12 HAM supplemented with 10\% FBS, $100 \mu \mathrm{g} / \mathrm{ml}$ kanamycin (Meiji Seika, Tokyo, Japan) and 1ng/ml of FGF2. Until the cells grew to confluence, they were cultured for the periods specified in the figure legends with FGF2; fresh medium was provided every 3 days. The mineralization microenvironment was created by treating TeSPDL cells at a density of $1 \mathrm{X} 10^{5} \mathrm{cell} / \mathrm{s} / \mathrm{cm}^{2}$ with $50 \mu \mathrm{g} / \mathrm{ml}$ ascorbic acid (Kanto Kagaku, Tokyo, Japan), $10 \mathrm{mM} \beta$-glycerophosphate (Kanto Kagaku) and $5 \mu \mathrm{M}$ dexamethasone (Wako) for 14 days. Fresh medium was provided every 3 days.

Reverse transcription polymerase chain reaction (RT-PCR)

Total RNA was extracted from the cells using Isogen (Nippongene Co., Toyama, Japan) according to the manufacturer's protocol. Complementary DNA (cDNA) was synthesized with Omniscript reverse transcriptase (Qiagen) using $(\mathrm{dT})_{15}$ primer $(1 \mu \mathrm{M})$. Subsequent amplification for the detection of TesPDL cell cDNAs was performed using the requisite number of cycles, under the following conditions: $94^{\circ} \mathrm{C}$ for $30 \mathrm{sec}$, annealing temperature optimized for each primer pair for $30 \mathrm{sec}$, and $72^{\circ} \mathrm{C}$ for $90 \mathrm{sec}$. The primer sequences used for PCR amplification (Table 1) were designed using cDNA sequences of 
mRNA for swine a1(I) procollagen (GenBank accession no. AY350905), swine osteopontin (GenBank NM214023, 843-1225 nt), swine periostin (GenBank AY880669, 16-495 nt), swine smooth mescle $\alpha$-actin (GenBank AF169349, 18-181 nt), swine Runt-related transcription factor (Runx) 2 (GenBank BX917855, 284-598 nt), swine vWF [13] (GenBank S78431, 489-792 nt), swine CD31 (GenBank NM213907, 1282-1774nt), swine VE-cadherin (GenBank AB046120, 2280-2587nt), swine osteocalcin (GenBank AW346755, 51-254 nt), human TERT (GenBank AB086379, 588-740 nt) and swine $\beta$-actin (GenBank U07786, 73-590 nt). All of the primers were synthesized by Hokkaido System Science (Sapporo, Japan). Amplified products were separated by agarose gel electrophoresis and stained with ethidium bromide. PCR experiments were performed using samples from at least three different cell preparations and the results were confirmed by triplicate PCR experiments from the same cell samples.

Detection of telomerase incorporation and assay for telomerase activity

The presence of hTERT in stable transfectants was confirmed by RT-PCR with primers specific for the telomerase and by assaying for telomerase activity. Telomerase activity was measured by a PCR-based telomerase repeat amplification protocol assay with TeloChaser (Toyobo) according to the manufacturer's instructions [14]. Briefly, 
TAG-U primer was mixed with crude cell extracts from TesPDL cells $\left(5 \times 10^{5}\right.$ cells for each reaction) or HeLa cells $\left(2.5 \times 10^{4}\right.$ cells for each reaction) and was incubated at $37^{\circ} \mathrm{C}$ for $60 \mathrm{~min}$ to produce telomeric repeats (5'-TTAGGG-3'). After the telomerase reaction, DNA was purified and amplified using CTA-R primer. The PCR products were fractionated by electrophoresis using $10 \%$ polyacrylamide gel electrophoresis and visualized by staining with ethidium bromide. An extract of HeLa cells was used as a positive control for telomerase activity.

Staining for alkaline phosphatase activity

The cells were stained for alkaline phosphatase (ALP) as previously described [15]. Briefly, cells in culture dishes were rinsed in phosphate-buffered saline, fixed in $100 \%$ methanol, rinsed with phosphate-buffered saline, and then overlaid with $5 \mathrm{ml}$ of $0.15 \mathrm{mg} / \mathrm{ml}$ 5-bromo-4 chloro-3-indolyphosphate (Wako, Osaka, Japan) plus $0.3 \mathrm{mg} / \mathrm{ml}$ of nitro-blue tetrazolium (Wako) in $0.1 \mathrm{M}$ Tris- $\mathrm{HCl}(\mathrm{pH} 9.0), 0.01 \mathrm{~N} \mathrm{NaOH}$ and $0.05 \mathrm{mM}$ $\mathrm{MgCl}_{2}$. They were then incubated at room temperature for $2 \mathrm{~h}$.

Von Kossa staining

Cells were fixed with $10 \%$ formalin in phosphate buffered saline $(\mathrm{pH} 7.2)$ for 30 
minutes. The dishes were washed with distilled water three times and then treated with fresh 5\% silver nitrate (Kanto Kagaku) for 30 minutes. They were washed again with distilled water at least three times, and developed with fresh 5\% sodium carbonate (Kanto Kagaku) in $25 \%$ formalin for 5 minutes. The dishes were then washed with distilled water three times, and fixed with 5\% sodium thiosulphate (Kanto Kagaku) for 2 minutes. After washing with distilled water, the specimens were examined under a phase-contrast microscope.

Immunocytochemical detection of vWF

Cultured TesPDL cells were fixed in acetone and permeabilized with $0.2 \%$ TritonX-100 in phosphate buffered saline. After background blocking in bovine serum albumin, the cells were incubated with both-anti-vWF rabbit antiserum (1:200; Dako, Carpinteria, CA) at room temperature for $1 \mathrm{~h}$. After washing off the primary antibodies, the cells were incubated with Alexa Fluor ${ }^{\circledR}$ 568-conjugated goat anti-rabbit IgG (1:200, Molecular Probes, Leiden, The Netherlands) for $45 \mathrm{~min}$ at room temperature. The cells were then washed three times in phosphate-buffered saline. Fluorescent images were obtained using a X40 objective with a Leica FW4000 (Leica) confocal laser scanning microscope. 


\section{RESULTS}

Characterization of clonal TesPDL cell lines

hTERT gene was transfected to Clawn miniature swine PDL cells, and then cloned 27 cell lines, designated TesPDL cells. Four cell lines, TesPDL1-4 cells, have been characterized. FGF2 is known to be a potent mitogen for several types of cell including bone marrow mesenchymal cells [16]. Therefore, FGF2 (1 ng/ml) was added to outgrowth cells from swine PDL tissues cultured in F-12 HAM supplemented with 10\% FBS, $100 \mu \mathrm{g} / \mathrm{ml}$ kanamycin. TesPDL1-4 cells did not enter a proliferative arrest after 30-50 population doublings (PD) indicating that immortalized cell lines had been established. In this experiments, the cells from PD 110 to 150 were used. TesPDL3 cells grew at a rate similar to TesPDL1, 2 and 4 cells (data not shown). The growth rates of TesPDL1-4 cells at PD150 are similar to these at PD 30, indicating stable proliferation of these cell lines beyond 150 days in cultures. TesPDL1-3 cells have a fibroblastic spindle-shape, but TesPDL4 cells appear polygonal (Fig. 1A).

Gene expression in TesPDL1-4 cells was analyzed by RT-PCR analysis. All four cell lines constitutively expressed mRNAs for ECM proteins of the PDL, that is procollagen $\alpha 1(\mathrm{I})$, osteopontin and periostin mRNA, although slight differences in their expression levels were observed (Fig. 1B). The cells also expressed smooth muscle 
$\alpha$-actin and Runx2 (Fig. 1B); these genes are expressed in PDL tissue [17, 18]. However, there were no differences in the amounts of these mRNAs among the established four cell lines. Staining for ALP activity showed the presence of the enzyme in the TesPDL1-4 cell lines. High ALP activity was observed in TesPDL2 and TesPDL3 cells (Fig. 1C). These observations indicate that these cells have the characteristics of PDL fibroblasts.

To confirm incorporation of ectopic hTERT gene in the immortalized cells, RT-PCR analysis was performed to detect hTERT mRNA and to assay for telomerase activity. As shown in Fig. 1B, hTERT mRNA was expressed in TesPDL1-4 cells, whereas hTERT transcripts were not detected in the pig kidney-derived epithelial cell line LLC-PK used as a negative control. Telomerase activity was also detected in non-heated extracts from TesPDL1-4 cell used as positive controls (Fig. 1D).

CD31, VE-cadherin and vWF mRNA expression in TesPDL3 cells

We investigated whether TesPDL3 cells had the potential to express the phenotype of vascular endothelial cells. The TesPDL3 cells were incubated in the presence of FGF2 for 2 days. VE-cadherin and vWF expression was detected in TesPDL3 cells by treatment with $1 \mathrm{ng} / \mathrm{ml}$ of FGF2. In contrast, CD31 expression could not detected by treatment of $1 \mathrm{ng} / \mathrm{ml} \mathrm{FGF2}$. This CD31 expression was detected in TesPDL3 cells by 
treatment of $10 \mathrm{ng} / \mathrm{ml} \mathrm{FGF} 2$ and a further increase at concentration of $20 \mathrm{ng} / \mathrm{ml}$ (Fig. 2A). Expression of VE-cadherin and vWF was also increased by high concentration of FGF2 but osteocalcin and ALP expression was not declined by FGF2 (Fig. 2A). The housekeeping gene $\beta$-actin was monitored as an internal control.

Further analysis of confocal immunofluorescence microscopy was performed to confirm protein expression of vWF in TesPDL3 cells. Cells of positive staining for vWF antibody were presence in TesPDL3 cells treated with $1 \mathrm{ng} / \mathrm{ml} \mathrm{FGF2,} \mathrm{and} \mathrm{vWF(+)} \mathrm{cells}$ increased by the treatment of $20 \mathrm{ng} / \mathrm{ml} \mathrm{FGF2} \mathrm{(Fig.} \mathrm{2B).}$

In vitro induction of mineralized nodule formation and induction of osteocalcin expression in TesPDL3 cells

To determine whether it was possible to induce the osteoblastic expression phenotype in TesPDL3 cells, we cultured the cells in the presence of ascorbic acid, $\beta$-glycerophosphate and dexamethasone for 14 days. These culture conditions were previously shown to give rise to cells that expressed numerous mRNAs characteristic of osteoblasts, including bone matrix proteins such as osteocalcin and matrix extracellular phosphoglycoprotein, and also showed in vitro induction of mineralized nodule formation characteristic of bone marrow mesenchymal cells [19, 20]. RT-PCR analyses 
of total RNA isolated from the cultured cells were performed to examine mRNA expression. Osteocalcin, osteopontin, ALP, and Runx2 mRNA expression increased with time in culture (Fig. 3A). Bone sialoprotein mRNA expression did not detect in these cells (data not shown). TesPDL1 cells also began to form nodules at 7 days after treatment; the multilayered cells then became polygonal in shape and formed nodules (data not shown). We used von Kossa staining to determine whether the nodules of the TesPDL3 and -4 cells were mineralized. Parts of the nodules showed darkly stained spots in TesPDL3 cells at 21 days after the treatment. However, no mineralization was observed in TesPDL4 cells (Fig. 3B). Our results indicate that TesPDL cell lines exhibit different extents of osteoblastic differentiation; TesPDL3 cells, in particular, have the ability to differentiate into osteoblasts in culture. 


\section{DISCUSSION}

Various tissue-specific cell lines have been immortalized using ectopic expression of hTERT, the catalytic subunit of the human telomerase enzyme $[21,22,23]$.

Normal PDL cells can proliferate in vitro for 20-30 PD before entering a proliferative arrest, commonly called senescence. To a considerable extent, incorporation of the hTERT gene resulted in cells being able to avoid senescence and to proliferate without limitation. Proliferation of the cells was enhanced by use of a substrate such as collagen I or poly-L-lysine (data not shown), indicating that the growth ability was influenced by interaction with specific extracellular matrix molecules. Within the heterogeneous cell population that comprises the PDL tissue, PDL fibroblasts are the predominant connective tissue cell type present. In morphology, TesPDL1 -4 cells have a fibroblastic cell appearance similar to that of primary PDL fibroblasts.

Previously several PDL immortalized cell lines have been established. D’Errico et al. [24] and Saito et al. [18] established a mouse PDL cell line utilizing SV40T-antigen gene transduction. Human PDL cell lines were also succeeded in established by SV40Tantigen gene transduction $[25,26]$. Recently, human PDL fibroblasts were immmotalized by hTERT gene transduction [27] or combination of SV40T-antigen and hTERT gene transduction [28]. These immotalized PDL cell lines expressed type I collagen, ALP, and 
periostin. Previous studies have shown that ALP activity increased and mineralizing nodule were produced by stimulation of bone morphogenetic protein-2 [18] or combination of ascorbic acid and $\beta$-glycerophosphate [27], indicating that the induction of osteoblastic phenotype were characterized in PDL fibroblasts. However, phenotype of vascular endothelial cells such as CD31, VE-cadherin and vWF expression has not been indicated in these PDL immortalized cell lines. This is a first report that the PDL cell line expressed vascular endothelial cell phenotype and provided a possibility that PDL fibroblastic progenitor cells could be differentiate vascular endothelial cell linage.

PDL fibroblasts produce numerous ECM proteins such as collagen I, III, XII, osteopontin and periostin [2]. In addition, expression of the cell membrane enzyme ALP and the transcription factor Runx2 is observed in PDL tissue and PDL fibroblasts in vivo [21]. Alpha-smooth muscle actin, an actin isoform strongly expressed by myofibroblasts and required for collagen's ability to contract, is expressed in PDL fibroblasts [29]. On the basis of gene expression patterns and of observations of cell morphology, we suggest that the TesPDL1-4 cell clones are PDL fibroblasts. PDL fibroblasts have the potential to differentiate into osteoblasts depending on the culture microenvironment. Rat bone marrow stromal cells cultured in the presence of dexamethasone, $\beta$-glycerophosphate and ascorbic acid have been shown to express several osteoblastic mRNAs, including 
osteocalcin, osteopontin and bone sialoprotein [19], and to form mineralized bone-like nodules in culture [30]. Extracellular calcified deposition and the inducible expression of osteocalcin in TesPDL3 cells indicated that TesPDL3 cells have the ability to differentiate into putative osteoblasts in the specific culture conditions applied here.

Inducible expression of VE-cadherin, CD31 and vWF was observed in TesPDL3 cells. Asahara et al (1997) reported that postnatal bone marrow contains endothelial progenitor cells that have the capacity to migrate to the peripheral circulation and to differentiate into mature endothelial cells [31]. During differentiation, endothelial progenitor cells obviously start to express CD31 (termed platelet endothelial cell adhesion molecule-1), VE- cadherin, and vWF. Mature endothelial cells show high levels of expression of vWF, VE- cadherin and fetal liver kinase (Flk)-1 (also termed kinase-insert domain-containing receptor or vascular endothelial growth factor receptor-2) [8]. Our results showing inducible expression of CD31, VE-cadherin and vWF in TesPDL3 cells, suggests that certain sub-populations of PDL fibroblasts can be induced to express the certain phenotype of vascular endothelial cells. Recently, side population fraction of human primary PDL cells expressed CD31 and VE-cadherin in specific culture conditions (personal communication). Therefore, it could exclude the possibility that TesPDL3 cell line is a one of some genes mutated cell line. Endothelial 
cells uniquely contain Weibel-Palade bodies, 0.1 micron wide, 3 micron long membrane-bound structures that represent the storage organelle for vWF [9]. However, we could not observe Weibel-Palade body-like structures in TesPDL3 cells. Expression of Flk-1 also could not detect in TesPDL3 cells (data not shown). Therefore, additional factors or stimuli might be required for full induction of expression of the vascular endothelial cell phenotype in our experimental system. Moreover, it is not yet clear whether our culture conditions increase the numbers of $\mathrm{vWF}(+)$ cells or increase expression levels in pre-existent vWF cells. Likewise, the mechanisms by which the culture conditions up-regulate the induction of vWF remain unknown.

Endothelial cells from different tissues and vessels display great heterogeneity in gene expression profiles [32]. Recently, Bronckers et al. (2005) reported that Runx2 expression was found in endothelial cells of developing vessels, skin, alveoli in developing bone, and developing PDL tissue [33]. It is possible that Runx2 expression in TesPDL3 cells might be required for endothelial or osteoblastic differentiation.

In conclusion, clonal PDL fibroblastic cell lines, derived from Clawn miniature swine PDLs, were established by transfection with hTERT gene. Several experiments indicated that, under appropriate conditions, TesPDL3 cells could be inducted to show the phenotypes of both vascular endothelial and osteoblastic cell lineages. These postnatal 
mesenchymal multipotent cells may be useful for tissue reconstruction following disease-related PDL damage. 


\section{REFERENCES}

[1] Ragnarsson B, Carr G., Daniel JC. Isolation and growth of human periodontal ligament cells in vitro. J. Dent. Res. 1985; 64: 1026-1030.

[2] Beertsen W, McCulloch CAG, Sodek J. The periodontal ligament: a unique, multifunctional connective tissue. 1997; Priodontol. 2000 13: 20-40.

[3] McCulloch CA. Progenitor cell populations in the periodontal ligament of mice. 1985; Anat. Rec. 211: 258-262.

[4] Pitaru S, Pritzki A, Bar-Kana I, Grosskopf A, Savion N, Narayanan AS. Bone morphogenetic protein 2 induces the expression of cementum attachment protein in human periodontal ligament clones. 2002; Connect. Tissue Res. 43: 257-264.

[5] Salingcarnboriboon R, Yoshitake H, Tsuji K, Obinata M, Amagasa T, Nifuji A, Noda M. Establishment of tendon-derived cell lines exhibiting pluripotent mesenchymal stem cell-like property. 2003; Exp. Cell Res. 287: 289-300.

[6] Nakamura T, Yamamoto M, Tamura M, Izumi Y. Effects of growth/differentiation factor-5 on human periodontal ligament cells. 2003; J. Periodontal. Res. 38: 597-605.

[7] Seo BM, Miura M, Gronthos S, Bartold PM, Batouli S, Brahim J, Young M, Robey PG, Wang CY, Shi S. Investigation of multipotent postnatal stem cells from human periodontal ligament, 2004; Lancet 364: 149-155.

[8] Hristov M, Erl W, Weber PC. Endothelial progenitor cells: mobilization, differentiation, and homing. 2003; Arterioscler. Thromb. Vasc. Biol. 23: 1185-1189.

[9] Denis CV. Molecular and cellular biology of von Willebrand factor. 2002; Int. J. Hematol. 75: 3-8.

[10] Bartold PM, Shi S, Gronthos S. Stem cells and periodontal regeneration. 2006; 
Periodontol. 2000 40: 164-172.

[11] Somerman MJ, Archer SY, Imm GR, Foster RA. A comparative study of human periodontal ligament cells and gingival fibroblasts in vitro. 1988; J. Dent. Res. 67: 66-70. [12] Meyerson M, Counter CM, Eaton EN, Ellisen LW, Steiner P, Caddle SD, Ziaugra L, Beijersbergen RL, Davidoff MJ, Liu Q, Bacchetti S, Haber DA. Weinberg RA. hEST2, the putative human telomerase catalytic subunit gene, is up-regulated in tumor cells and during immortalization. 1997; Cell 90: 785-795.

[13] Bahnak BR, Lavergne JM, Ferreira V, Kerbiriou-Nabias D, Meyer D. Comparison of the primary structure of the functional domains of human and porcine von Willebrand factor that mediate platelet adhesion. 1992; Biochem. Biophys. Res. Commun. 182: $561-568$.

[14] Tatematsu K, Nakayama J, Danbara M, Shionoya S, Sato H, Omine M, Ishikawa F. A novel quantitative 'stretch PCR assay', that detects a dramatic increase in telomerase activity during the progression of myeloid leukemias. 1996; Oncogene 13: 2265-2274.

[15] Nakashima A, Katagiri T, Tamura M. Cross-talk between Wnt and bone morphogenetic protein (BMP)- 2 signaling in differentiation pathway of $\mathrm{C} 2 \mathrm{C} 12$ myoblasts. 2005; J. Biol. Chem. 280: 37660-37668.

[16] Bikfalvi A, Klein S, Pintucci G, Rifkin DB. Biological roles of fibroblast growth factor-2. 1997; Endocr. Rev. 18: 26-45.

[17] Giannopoulou C, Cimasoni G. Functional characteristics of gingival and periodontal ligament fibroblasts. 1996; J. Dent. Res. 75: 895-902.

[18] Saito Y, Yoshizawa T, Takizawa F, Ikegame M, Ishibashi O, Okuda K, Hara K, Ishibashi K, Obinata M, Kawashima H. A cell line with characteristics of the periodontal ligament fibroblasts is negatively regulated for mineralization and Runx $2 / \mathrm{Cbfa} 1 / \mathrm{Osf} 2$ 
activity, part of which can be overcome by bone morphogenetic protein-2. 2002; J. Cell Sci. 115: 4191-4200.

[19] Yao KL, Todescan JrR, Sodek J. Temporal changes in matrix protein synthesis and mRNA expression during mineralized tissue formation by adult rat bone marrow cells in culture. 1994; J. Bone Miner. Res. 9: 231-240.

[20] Zhang GX, Mizuno M, Tsuji K, Tamura M. Regulation of mRNA expression of matrix extracellular phosphoglycoprotein (MEPE)/ osteoblast/osteocyte factor 45 (OF45) by fibroblast growth factor 2 in cultures of rat bone marrow-derived osteoblastic cells. 2004; Endocrine 24: 15-24.

[21] Hooijberg E, Ruizendaal JJ, Snijders PJ, Kueter EW, Walboomers JM, Spits H. Immortalization of human CD8 $+\mathrm{T}$ cell clones by ectopic expression of telomerase reverse transcriptase. 2000; J. Immunol. 165: 4239-4245.

[22] O'Hare MJ, Bond J, Clarke C, Takeuchi Y, Atherton AJ, Berry C, Moody J, Silver A R, Davies DC, Alsop AE, Neville AM, Jat PS. Conditional immortalization of freshly isolated human mammary fibroblasts and endothelial cells. 2001; Proc. Natl. Acad. Sci. U S A. 98: 646-651.

[23] Hao J, Narayanan K, Ramachandran A, He G, Almushayt A, Evans C, George A. Odontoblast cells immortalized by telomerase produce mineralized dentin-like tissue both in vitro and in vivo. 2002; J. Biol. Chem. 277: 19976-19981.

[24] D'Errico JA, Ouyang H, Berry JE, MacNeil RL, Strayhorn C, Imperiale MJ, Harris NL, Goldberg H, Somerman MJ. Immortalized cementoblasts and periodontal ligament cells in culture. 1999; Bone 25: 39-47.

[25] Hoang AM, Chen D, Oates TW, Jiang C, Harris SE, Cochran DL. Development and characterization of a transformed human periodontal ligament cell line. 1997; $J$. 
Periodontol. 68:1054-1062.

[26] Parkar MH, Kuru L, O'Hare M, Newman HN, Hughes F, Olsen I. Retroviral transduction of human periodontal cells with a temperature-sensitive SV40 large T antigen. 1999; Arch. Oral Biol. 44:823-834.

[27] Fujita T, Otsuka-Tanaka Y, Tahara H, Ide T, Abiko Y, Mega J. Establishment of immortalized clonal cells derived from periodontal ligament cells by induction of the hTERT gene. 2005; J. Oral Sci. 47:177-184.

[28] Fujii S, Maeda H, Wada N, Kano Y, Akamine A. Establishing and characterizing human periodontal ligament fibroblasts immortalized by SV40T-antigen and hTERT gene transfer. 2006; Cell Tissue Res. 324:117-125.

[29] Arora PD, McCulloch CA. Dependence of collagen remodelling on alpha-smooth muscle actin expression by fibroblasts. 1994; J. Cell. Physiol. 159: 161-175.

[30] Maniatopoulos C, Sodek J, Melcher AH. Bone formation in vitro by stromal cells obtained from bone marrow of young adult rats. 1988; Cell Tissue Res. 254: 317-330.

[31] Asahara T, Murohara T, Sullivan A, Silver M, van der Zee R, Li T, Witzenbichler B, Schatteman G, Isner JM. Isolation of putative progenitor endothelial cells for angiogenesis. 1997; Science 275:964-967.

[32] Sumpio BE, Riley JT, Dardik A. Cells in focus: endothelial cell. 2002; Int. J. Biochem. Cell Biol. 34:1508-1512.

[33] Bronckers ALJJ, Sasaguri K, Cavender AC, D’Souza RN, Engelse M A. Expression of Runx2/Cbfa1/Pebp $2 \alpha \mathrm{A}$ during angiogenesis in postnatal rodent and fetal human orofacial tissues. 2005; J. Bone. Miner. Res. 20: 428-437. 
A
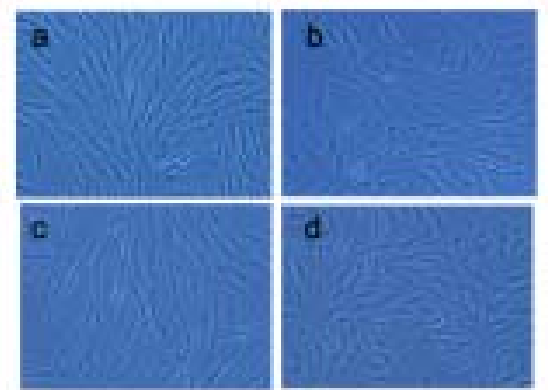

B

a.1(I)procollagen

osteopontin periostin

SM $\alpha$-actin

Run×2

hTERT

$\beta$-actin

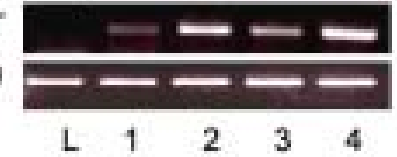

C a

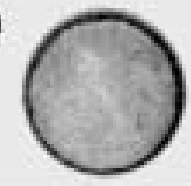

c.

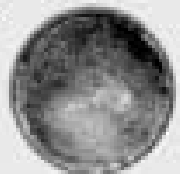

D

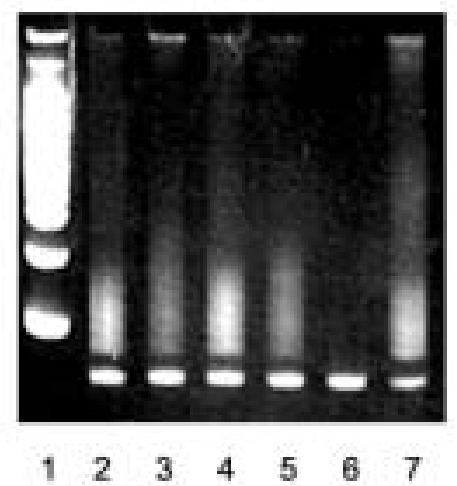

Fig. 1 
Fig. 2

A
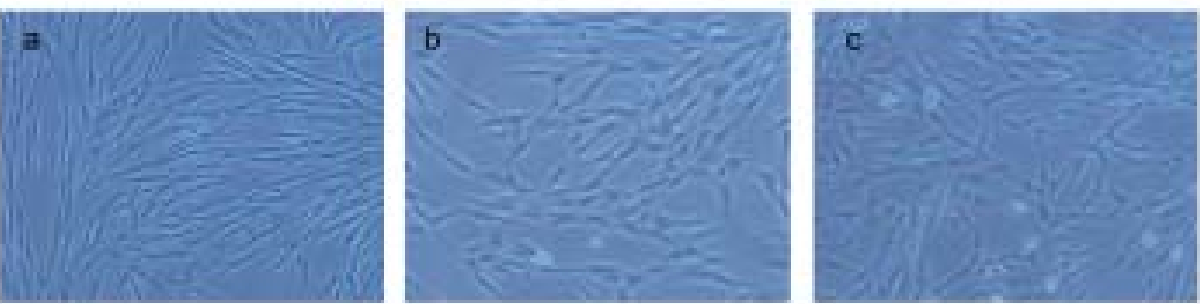

B

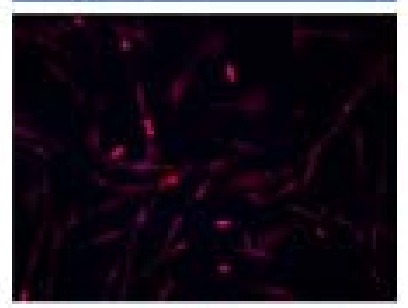

CD31

VE-cadherin

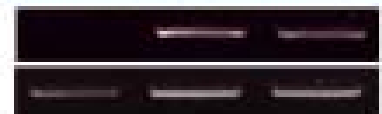

WWF

CD34

osteocalcin

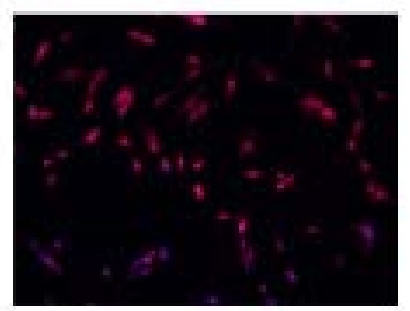

Alkaline phosphatase

B-actin
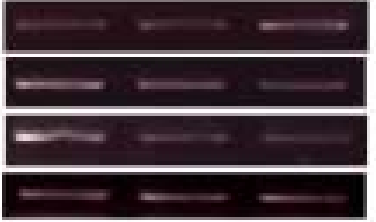

$5 \frac{2}{10}$

(ng/ml) 
Fig.3

A

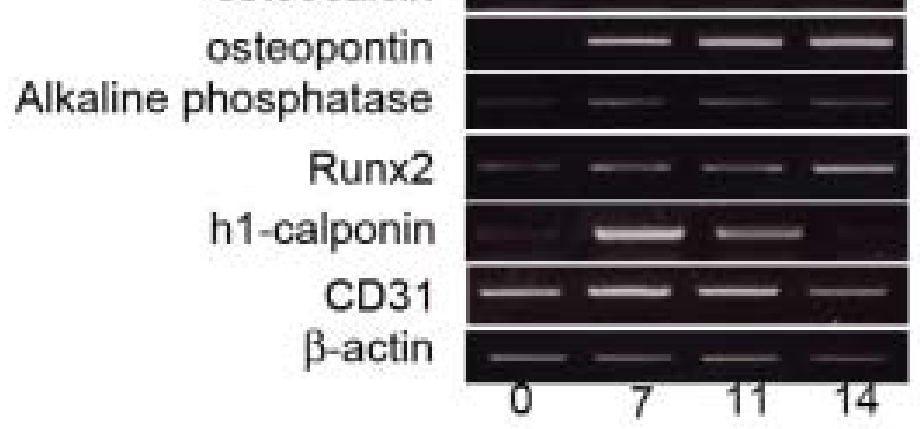

(day)

B
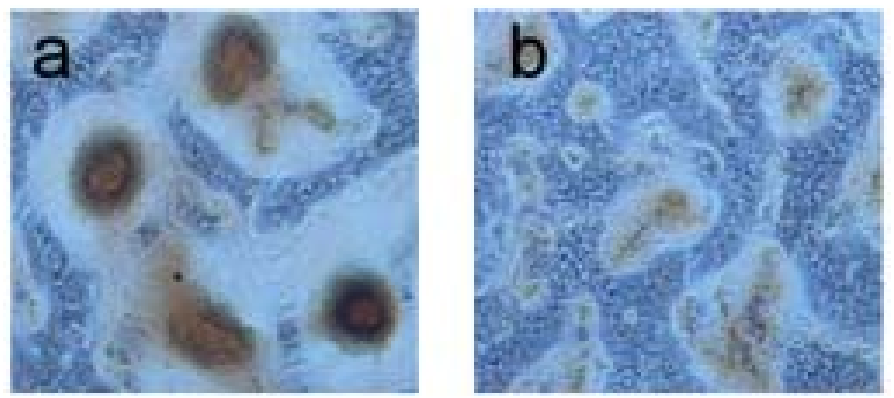


\section{Figure Legends}

Figure 1

Establishment and characterization of TesPDL cells

Clawn miniature swine PDL cells were obtained from a premolar extracted from a mandible. Outgrowth cells were cultured and transfected with the pCI-Neo-hTERT plasmid. Two days after transfection, the medium was changed to F12 containing geneticin at $0.1 \mu \mathrm{g} / \mathrm{ml}$. The cells were passaged, and clones were selected by limiting dilution and designated as TesPDL cells. A: Cell morphology viewed by phase contrast microscopy. TesPDL1 (a), -2 (b), -3 (c) and -4 cells (d) cells were plated at 1 X10 cells $/ \mathrm{cm}^{2}$ in type I collagen-coated culture dishes and cultured for $24 \mathrm{~h}$. Magnification: X100. B: Reverse transcriptase polymerase chain reaction (RT-PCR) analysis. TesPDL1 (lane 1), -2 (lane 2), -3 (lane 3) and -4 cells (lane 4) or LLC-PK (lane L) cells were plated at $1 \mathrm{X} 10^{5}$ cells $/ \mathrm{cm}^{2}$ in $100 \mathrm{~mm}$ cell culture dishes and cultured for $48 \mathrm{~h}$. Total cellular RNA was extracted and RT-PCR was performed to examine the levels of mRNA expression. The PCR products were separated on a $2 \%$ agarose gel containing ethidium bromide, and then observed on an ultraviolet transilluminator. Equal loading of cDNA samples was confirmed by amplification of $\beta$-actin cDNA. These data represent one of three independent experiments with similar results. C: Staining for alkaline phosphatase 
(ALP) activity. TesPDL1 (a), -2 (b), -3 (c) and -4 cells (d) cells were plated at 1 X10 cells $/ \mathrm{cm}^{2}$ in $100 \mathrm{~mm}$ cell culture dishes and cultured for 4 days. ALP staining for cells was performed as described in the Materials and Methods. D: Telomerase activity was measured by a PCR-based telomerase repeat amplification protocol assay with TeloChaser as described in the Materials and Methods. The PCR products were fractionated by electrophoresis on a $10 \%$ polyacrylamide gel and visualized by staining with ethidium bromide. 100 bp marker (lane 1), TesPDL1 cells (lane 2), -2 cells (lane 3), -3 cells (lane 4) and -4 cells (lane 5). Lysis solution served as a negative control (lane 6). An extract of HeLa cells was used as a positive control for telomerase activity (lane 7).

Figure 2

Expression of CD31, vascular endothelial cadherin (VE-cadherin) and von Willebrand factor (vWF) in TesPDL3 cells

TesPDL 3 cells were plated at $1 \times 10^{5}$ cells $/ \mathrm{cm}^{2}$ in $100 \mathrm{~mm}$ cell culture dishes and cultured for $48 \mathrm{~h}$ with the indicated doses FGF2. A: Total cellular RNA was extracted and then RT-PCR was performed to determine levels of mRNA expression. B: Immunocytochemical staining for von Willebrand factor (vWF). TesPDL3 cells were cultured with $1 \mathrm{ng} / \mathrm{ml}$ (a) or $20 \mathrm{ng} / \mathrm{ml}$ (b) of FGF2 for 2 days. The cells were then 
removed from culture dishes using trypsin/EDTA, attached to slides, and stained with antibody for vWF. Magnification X400.

Figure 3

In vitro induction of mineralized nodule formation and induction of osteocalcin expression in TesPDL3 cells

TeSPDL 3 and -4 cells, both at a density of $1 \times 10^{5}$ cells $/ \mathrm{cm}^{2}$, were cultured in the presence of $50 \mu \mathrm{g} / \mathrm{ml}$ ascorbic acid, $10 \mathrm{mM} \beta$-glycerophosphate and $5 \mu \mathrm{M}$ dexamethasone. A: Total cellular RNA was extracted from TesPDL3 cells at the indicated days of incubation. RT-PCR was performed to determine the levels of mRNA expression as described in the Materials and Methods. B: von Kossa staining of TesPDL3 cells (a) or -4 cells (b) after 21 days of culture. Magnification X100. 
Table 1

Primers used for RT-PCR

\begin{tabular}{|c|c|c|c|}
\hline Specificity & Oligonucleotide sequence (5’-3’) & $\begin{array}{l}\text { Anneal } \\
\text {. Temp. }\end{array}$ & $\begin{array}{c}\text { Predicte } \\
\text { d size } \\
(\mathrm{bp})\end{array}$ \\
\hline a1(I) & GATCCTGCTGACGTGGCCAT & & \\
\hline procollagen & ACTCGTGCAGCCGTCGTAGA & & 212 \\
\hline \multirow[t]{2}{*}{ osteopontin } & GCAATGAGCATTCCAATGTG & & \\
\hline & GACCGTCGACTAAACCCTGA & & 383 \\
\hline \multirow[t]{2}{*}{ periostin } & CCACGGAGGTGCGTTATTTA & & \\
\hline & GAGCCAACAGGCAAGCTAA & & 480 \\
\hline \multirow{2}{*}{$\begin{array}{l}\text { smooth muscle } \\
\alpha \text {-actin }\end{array}$} & ATCACCAATTGGGACGACAT & & \\
\hline & GGGACGTTGAAGGTCTCAAA & & 164 \\
\hline \multirow[t]{2}{*}{ Runx2 } & GGTACCAGATGGGACTGTGG & & \\
\hline & ATGCGCCCTAAATCACTGAG & & 315 \\
\hline \multirow[t]{2}{*}{$\mathrm{vWF}$} & GGGCCTGAAGAAGAAGAAGG & & \\
\hline & TTCCAGCACAAACACCACAT & & 304 \\
\hline \multirow[t]{2}{*}{ VE-cadherin } & CGACTCATCCGACTCTGACA & & \\
\hline & CCCAGACAGAACACCATCCT & & \\
\hline \multirow[t]{2}{*}{ h1-calponin } & GGCTGAGGTCAAGAACAAGC & & \\
\hline & CCAGTTCTGGGTGGACTCAT & & 202 \\
\hline \multirow[t]{2}{*}{ CD31 } & GCAAGGTGGTCAAGAGAAGC & & \\
\hline & GCCTGGGTGTCATTCAAAGT & & 493 \\
\hline \multirow[t]{2}{*}{ osteocalcin } & TCAACCCCGACTGCGACGAG & & \\
\hline & TTGGAGCAGCTGGGATGATGG & & 204 \\
\hline \multirow[t]{2}{*}{ hTERT } & TCTGGGATGCGAACGGGC & & \\
\hline & TCCGGCTCAGGGGCAGC & & 153 \\
\hline \multirow[t]{2}{*}{$\beta$-actin } & CGCACCACTGGCATTGTCAT & & \\
\hline & GCCGTGATCTCCTTCTGCAT & & 518 \\
\hline
\end{tabular}

Runx2, Runt-related transcription factor 2; vWF, von Willebrand factor; VE-cadherin, vascular endothelial-cadherin; hTERT: human telomerase reverse transcriptase 